\title{
Medidas regulatorias en agua potable y saneamiento, expedidas por el Gobierno colombiano en el marco de la emergencia económica, social y ecológica, con ocasión de la pandemia de covid-19*
}

Judith Sofía Echeverría Molina ${ }^{a}$

\begin{abstract}
Resumen: el artículo presenta un análisis de las disposiciones transitorias emitidas por el Gobierno de Colombia y la Comisión de Regulación de Agua Potable y Saneamiento Básico, en relación con los servicios públicos domiciliarios (SPD), en desarrollo de la declaratoria del Estado de Emergencia Económica, Social y Ecológica en el territorio nacional, por motivo de la pandemia de covid-19. Luego de explicar el alcance de las disposiciones emanadas del Ejecutivo, la investigación plantea como objetivo central analizar los retos y oportunidades para la implementación de políticas públicas, las cuales deben ser redireccionadas a partir de las experiencias que deja el distanciamiento social. La metodología utilizada consistió en el análisis e interpretación de las normas de excepción expedidas por el Gobierno, frente a las disposiciones constitucionales y legales que regulan los SPD. Se concluye que, primero, es posible hacer cambios en la política pública de SPD en el caso de los servicios de agua potable y saneamiento básico y, segundo, se consiguió que las personas empezaran a hacer una asociación necesaria: la relación entre el consumo con el precio de los servicios.
\end{abstract}

Palabras clave: agua potable; estado de excepción; pandemia; saneamiento básico; servicios públicos domiciliarios Recibido: 09 de agosto de 2020

Aceptado: 24 de marzo de 2021

Disponible en línea: 06 de agosto de 2021

Cómo citar: Echeverría Molina, J. S. (2021). Medidas regulatorias en agua potable y saneamiento, expedidas por el Gobierno colombiano en el marco de la emergencia económica, social y ecológica, con ocasión de la pandemia de COVID-19. Prolegómenos, 24(47), 99-116. https://doi.org/10.18359/prole.5107

* Artículo de investigación.

a Abogada, Universidad del Norte; especialista en Derecho de Sociedades, Universidad Javeriana, y en Estudios Políticos Económicos, Universidad del Norte; magíster en Desarrollo Social, Universidad del Norte, y máster 2 année Sciences de la Société, Université Paris XII Val de Marne. Profesora del Departamento de Derecho en la Universidad del Norte; miembro del grupo de investigaciones en Derecho y Ciencia Política (gigecp) y profesora de posgrado en temas de servicios públicos domiciliaros e investigación jurídica. Universidad del Norte, Barranquilla, Colombia.

Correo electrónico: jechever@uninorte.edu.co ORCID: https://orcid.org/0000-0001-7326-5577 


\title{
Regulatory Measures in Drinking Water and Sanitation, Issued by the Colombian Government in the Framework of the Economic, Social and Ecological Emergency, on the Occasion of the COVID-19 Pandemic
}

\begin{abstract}
Summary: the article presents an analysis of the transitory provisions issued by the Government of Colombia and the Commission for the Regulation of Drinking Water and Basic Sanitation, in relation to home public services (SPD), concerning the declaration of the State of Economic, Social and Ecological Emergency in the national territory, due to the COVID-19 pandemic. After explaining the scope of the provisions issued by the Executive, the main objective of the research is to analyze challenges and opportunities for the implementation of public policies, which must be redirected from the experiences left by social distancing. The methodology used consisted in the analysis and interpretation of the exception norms issued by the Government, concerning the constitutional and legal provisions that regulate the SPD. It is concluded that, first, it is possible to make changes in the SPD public policies regarding drinking water and basic sanitation services and, secondly, people began to make a necessary association: the relationship between consumption and the price of services.
\end{abstract}

Keywords: drinking water; state of emergency; pandemic; basic sanitation; home public services

\section{Medidas regulatórias quanto a água potável e saneamento básico expedidas pelo governo colombiano no âmbito da emergência econômica, social e ecológica devido à pandemia da COVID-19}

\begin{abstract}
Resumo: neste artigo, apresenta-se uma análise das medidas transitórias emitidas pelo governo da Colômbia e pela Comissão de Regulamentação de Água Potável e do Saneamento Básico, quanto aos serviços públicos domiciliares (spd), em desenvolvimento para a declaração do estado de emergência econômica, social e ecológica no território nacional ante a pandemia ocasionada pela COVID-19. Após explicar o escopo das disposições emanadas pelo Executivo, nesta pesquisa, propõe-se, como objetivo principal, analisar os desafios e as oportunidades para implementar políticas públicas, as quais devem ser repensadas a partir das experiências que o distanciamento social deixa. A metodologia utilizada consistiu na análise e na interpretação das normas de exceção expedidas pelo governo, ante as disposições constitucionais e legais que regulamentam os spd. Conclui-se que, primeiro, é possível fazer mudanças na política pública dos spd no caso dos serviços de água potável e saneamento básico; segundo, foi possível que as pessoas começassem a fazer uma associação necessária: a relação entre o consumo com o preço dos serviços.
\end{abstract}

Palavras-chave: água potável; estado de exceção; pandemia; saneamento básico; serviços públicos domiciliares 


\section{Introducción}

Las medidas regulatorias transitorias tomadas por el Gobierno colombiano frente a la emergencia causada por el Covid-19 son producto de la declaratoria de un estado de excepción. Estas medidas, útiles para afrontar crisis como la de la pandemia, pudieron verse como una oportunidad para analizar la política de subsidios, en relación con los servicios públicos domiciliarios (SPD) de agua potable y saneamiento básico. Esta política, vigente en el país, favorece, concretamente, a los usuarios de menores ingresos. Con ello en mente, el objetivo de este trabajo fue analizar las medidas transitorias que tomó el Gobierno nacional frente a los SPD, específicamente, los de agua potable y saneamiento básico. Para ello, es necesario hacer una revisión general sobre el concepto de estado de excepción, consagrado en la Constitución Política (1991).

Es importante resaltar que no se ahonda en las motivaciones y la constitucionalidad de la medida que, en algunas ocasiones en que se ha invocado esta figura, ha sido declarada inexequible por aspectos formales por la Corte Constitucional; tampoco se profundiza en el sistema de controles que, por disposición constitucional, tienen este tipo de decretos. No obstante, presentamos el alcance de cada disposición y, de forma predictiva, planteamos propuestas para que sean incluidas cuando se asuma la "nueva normalidad", como se ha denominado a lo que se cree que vendrá después de esta crisis mundial.

El trabajo está dividido en cinco partes. Se inicia con un repaso sobre los estados de excepción en Colombia; luego se explica el alcance de los Decretos del Estado de Excepción y Servicios Públicos Domiciliarios. Seguidamente, se hace una reflexión sobre los sectores afectados con las medidas de emergencia; así como los desafíos para el sector rural y los usuarios del sector industrial y comercial.

En cuanto a la metodología, se parte del objetivo de explicar el alcance de las medidas regulatorias en agua potable y saneamiento, expedidas por el Gobierno colombiano en el marco de la emergencia económica, social y ecológica, derivada de la pandemia de covid-19. Es una metodología explicativa documental que se basa en las disposiciones normativas emanadas por el Ejecutivo en 2020, para afrontar y responder por los desafíos de la pandemia en los ámbitos sociales e institucionales de Colombia.

\section{Estados de excepción en Colombia}

Los artículos 212-215 de la Constitución definen de manera clara los estados de excepción, e ilustra las condiciones que deben cumplirse para dicha declaratoria. Lo primero que debemos conocer es el concepto de estado de excepción, que puede definirse "como aquella situación extraordinaria generada por un periodo de crisis, donde uno o alguno de poderes del Gobierno dispone de poderes excepcionales para de garantizar la 'continuidad de los servicios públicos' o sus funciones esenciales" (Llugdar, 2020, p. 95).

El artículo constitucional 212 se refiere al estado de guerra exterior como aquel que puede ser declarado por el Gobierno, con el fin de "repeler la agresión, defender la soberanía, atender los requerimientos de la guerra, y procurar el restablecimiento de la normalidad".

El siguiente artículo 213 de la Constitución, a su vez, se refiere a las facultades presidenciales para la declaratoria de un estado de excepción:

en caso de grave perturbación del orden público que atente de manera inminente contra la estabilidad institucional, la seguridad del Estado, o la convivencia ciudadana, y que no pueda ser conjurada mediante el uso de las atribuciones ordinarias de las autoridades de Policía, el presidente de la República, con la firma de todos los ministros, podrá declarar el Estado de Conmoción Interior, en toda la República o parte de ella, por término no mayor de noventa días, prorrogable hasta por dos periodos iguales, el segundo de los cuales requiere concepto previo y favorable del Senado de la República [...]. Mediante tal declaración, el Gobierno tendrá las facultades estrictamente necesarias para conjurar las causas de la perturbación e impedir la extensión de sus efectos [...]. Los decretos legislativos que dicte el Gobierno podrán suspender las leyes incompatibles con el Estado de Conmoción Interior, y dejarán de regir tan pronto como se declare restablecido el 
orden público. El Gobierno podrá prorrogar su vigencia hasta por noventa días más [...]. Dentro de los tres días siguientes a la declaratoria o prórroga del Estado de Conmoción Interior, el Congreso se reunirá por derecho propio, con la plenitud de sus atribuciones constitucionales y legales. El presidente le pasará inmediatamente un informe motivado sobre las razones que determinaron la declaración.

Como medida extraordinaria, pero en busca de garantizar el orden económico y social, seguidamente, el artículo constitucional 215 establece lo siguiente:

Cuando sobrevengan hechos distintos de los previstos en los artículos 212 y 213 que perturben o amenacen perturbar en forma grave e inminente el orden económico, social y ecológico del país, o que constituyan grave calamidad pública, podrá el presidente, con la firma de todos los ministros, declarar el Estado de Emergencia por periodos hasta de treinta días en cada caso, que sumados no podrán exceder de noventa días en el año calendario [...]. Mediante tal declaración, que deberá ser motivada, podrá el presidente, con la firma de todos los ministros, dictar decretos con fuerza de ley, destinados exclusivamente a conjurar la crisis y a impedir la extensión de sus efectos.

Cabe resaltar que este aparte del artículo 215 no se cumplió por parte del Ejecutivo en la declaración de estado de emergencia por Covid-19 y, a falta de unas firmas, los decretos fueron declarados inexequibles, luego de ser revisados por la Corte Constitucional. Sin embargo, llegaron a surtir reacciones y efectos sobre los usuarios y las empresas.

Luego de la lectura de los artículos anteriores, vemos que se trata de una facultad extraordinaria del presidente y que estas medidas,

por naturaleza, delimitan la frontera entre normalidad y anormalidad, en el desarrollo del ordenamiento constitucional, puesto que solo se ponen en marcha ante una situación de anormalidad, y traen consigo una serie de limitaciones y facultades que impiden el retorno a la normalidad. (Tobón y Mendieta, 2017 p. 69)

Con base en las anteriores disposiciones constitucionales, en 1994 se expidió la Ley 137 de 1994, que reglamenta los estados de excepción y regula de manera precisa los pasos a seguir en caso de la existencia de circunstancia para cada declaratoria.

Es significativo aclarar que no toda alteración o situación crítica que viva el Estado lleva al Ejecutivo a la declaratoria de un estado de excepción, sino que debe ser muy preciso, en el detalle, para no incurrir en excesos. Asimismo, es condición que la declaratoria permita superar la situación o, en el caso particular de la pandemia, que las medidas permitan sobrellevar la situación y no hacerla más gravosa para la comunidad. Por tal razón, las normas que se profieran dentro de esa declaratoria de emergencia deben ser coherentes con las circunstancias que le dieron origen.

Se advierte que la declaratoria del Estado de Emergencia Económica, Social y Ecológica tampoco representa algo novedoso en el país, ya otros presidentes habían usado esa herramienta ${ }^{1}$. Por ejemplo, el Decreto 1178 de 1994 por la emergencia derivada de la avalancha y desbordamiento del Río Páez en el departamento de Cauca; también el Decreto 195 de 1999, por causa de un terremoto, limitado a los departamentos y municipios afectados por el terremoto; así como el Decreto 4580 de 2010, para afrontar los efectos en ese año, causados por el fenómeno de la Niña en el país (Corte Constitucional, Sentencia C-216, 2011).

En cuanto a este tipo de declaratorias de Estados de Emergencia, Vanegas (2011) menciona que la figura de poderes excepcionales

casi siempre ha estado presente en nuestro constitucionalismo, desde los albores de nuestra vida independiente, no solo por su consagración formal en los textos superiores, sino también, y esto sí con mayor preocupación, por el uso exagerado y abusivo, declarado o no, que se hizo de dichas facultades extraordinarias en tiempos de crisis, que terminaron por convertirla en fuente de 'necrosis constitucional'. (p. 262)

De la misma manera, otros Estados de América Latina, como Argentina, Bolivia, Brasil, Chile, Ecuador, México, Paraguay, Perú, Uruguay y Venezuela, lo tienen contenido en sus constituciones, para efectos similares a los previstos en Colombia

1 Hasta 2015, había sido invocada en doce ocasiones (Mira-González, 2016). 
(Ylarri, 2020). Asimismo, la defensa es sumamente evidente; sin embargo,

la justificación del estado de excepción resulta un prerrequisito fundamental para su declaración, de donde debemos inferir un carácter de "necesariedad" para la invocación de esta figura jurídica, esto es, si no concurren circunstancias justificantes suficientes de este mecanismo, consideramos que se habilitan las alternativas jurídicas para su revisión. (Figueroa, 2020, p. 414)

El artículo constitucional 215 justifica la declaratoria de emergencia en el país, en situación de la pandemia del Covid-19. Cuando se mencionan estos Estados de Excepción, por lo regular, se alude a situaciones relacionadas con afectaciones al medioambiente, daño a los recursos naturales o desastres, etc. Pero pocas veces se pensó dar como ejemplo hipotético un virus y, mucho menos, una pandemia que viene siendo la que nos ocupa.

Cabe resaltar que los estados de excepción no generan facultades ilimitadas para el Ejecutivo. Por ejemplo, muchas de las disposiciones que se profirieron en desarrollo de esas facultades cuidaron de no ir contra la Constitución y la ley. En este caso, en la Ley de Servicios Públicos Domiciliarios (cuando aumenta la base porcentual para el otorgamiento de subsidios), sin perjuicio del sistema de controles que la misma constitución establece ${ }^{2}$.

2 el artículo 215, el parágrafo establece: “El Gobierno enviará a la Corte Constitucional al día siguiente de su expedición los decretos legislativos que dicte [...], para que aquella decida sobre su constitucionalidad. Si el Gobierno no cumpliere con el deber de enviarlos, la Corte Constitucional aprehenderá de oficio y en forma inmediata su conocimiento". En el mismo artículo reza: "El Congreso, durante el año siguiente a la declaratoria de la emergencia, podrá derogar, modificar o adicionar los decretos a que se refiere este artículo, en aquellas materias que ordinariamente son de iniciativa del Gobierno. En relación con aquellas que son de iniciativa de sus miembros, el Congreso podrá ejercer dichas atribuciones en todo tiempo". De otra parte, "el Congreso examinará el informe motivado presentado por el Gobierno y se pronunciará expresamente sobre la conveniencia y oportunidad de las medidas adoptadas (art. 215). Dentro del año siguiente a la declaratoria de
Adicionalmente, es importante destacar que, aunque estos decretos no lograron la exequibilidad de la Corte Constitucional, por no cumplir a cabalidad con los requisitos de forma, ello no implica que su impacto invitara a redireccionar la política pública frente a los servicios de agua potable y saneamiento, a partir de lo sucedido y los resultados que alcanzaron a generar los decretos.

\section{Decretos del estado de excepción y servicios públicos domiciliarios}

Ante la situación generada por la pandemia, los desafíos del Estado colombiano han sido inmensos, no solo en el proceso de calamidad, sino en las situaciones que podrían generarse a futuro, ya que muchos hábitos pudieron modificarse. Todo ello constituye una oportunidad para la política pública del sector de los servicios públicos; también para el cuidado del medioambiente. Adicionalmente, debido a que, frente a

las obligaciones específicas relacionadas con el acceso al agua potable y el saneamiento se han venido reconociendo también, en medida creciente, en los principales tratados de derechos humanos, fundamentalmente como parte del derecho a un nivel de vida adecuado y del derecho a la salud. (ONUHábitat, 2018, p. 6)

Ante esta situación imprevisible y altamente excepcional, no solo para Colombia sino para el resto del mundo, el Estado debe dar respuestas a la comunidad para garantizar sus derechos o reducir cuanto sea posible su afectación.

A pesar de la parálisis que se evidenció en Colombia, los SPD siguieron su ritmo. Podría afirmarse que, a mayor velocidad, ya que, por las exigencias del confinamiento, no descasan, no tienen tregua, por tratarse de servicios esenciales ${ }^{3}$. A la vez, porque garantizan que otros derechos sean continuos, eficientes y accesibles, como son

la emergencia, el Congreso podrá derogar, modificar o adicionar los decretos dictados, inclusive en aquellas materias que ordinariamente son de iniciativa del Gobierno" (Cifuentes, 2002. p. 2).

3 La Ley 142 de 1994 dice sostiene: "Todos los servicios públicos, de que trata la presente Ley, se considerarán servicios públicos esenciales” (art. 4). 
los servicios de salud (centro de la pandemia) y el derecho a la vivienda, entre otros. Ello se evidencia con las tareas de reconexión ordenadas por el Ejecutivo o las laborales para llevar agua de forma prioritaria en cisternas a lugares apartados del país (Asociación Nacional de Empresas de Servicios Públicos y de Comunicaciones -Andesco, 2020).

Para comprender el alcance de las medidas mencionadas, también es preponderante recordar algunos aspectos de la política pública para el sector de los SPD y el marco constitucional, legal y regulatorio.

En Colombia, con la expedición de la Ley 142 de 1994 cambió la política de gestión de los servicios públicos domiciliarios. A partir de ese momento, con base en lo previsto el artículo 365 de la Constitución Política, los particulares también participan en la gestión y operación de las infraestructuras estatales de los servicios públicos (Echeverría y Nieto, 2017).

Lo anterior es muy importante, ya que en la medida en que comprendemos que las decisiones tomadas por el Estado debido a la pandemia, si bien forman parte de las facultades previstas en la Constitución, también hay que tener en cuenta que existen usuarios, empresas y condicionamientos, para garantizar la operación, calidad y gestión de los SPD. Tales condicionamientos, luego de superada la crisis, son de obligatorio cumplimiento para todos y dan sentido a los previstos en las normas transitorias, las cuales para el común de los habitantes pudieran parecer insuficientes.

De esta manera, conforme con la política pública reinante en el país, "más del $53 \%$ de los usuarios de acueducto y alcantarillado son atendidos por empresas cuyo principal aporte de capital proviene del sector estatal; y tan solo el 19,3\% de los usuarios son atendidos por empresas cuyo aporte de capital es totalmente privado" (Dirección Nacional de Planeación -DNP y Superintendencia de Servicios Públicos Domiciliarios, 2018, p. 10). Como se ve, gracias a este modelo, el Estado tuvo mayor libertad de acción en la medida que un pequeño porcentaje de empresas tiene la operación y la gestión de capital privado, hecho que facilita las maniobras, por no existir privatización de los servicios públicos en Colombia. Además, la poca participación privada se da para la operación de las infraestructuras, lo cual se hizo como subsidio a la demanda contra el presupuesto estatal.

También es oportuno mencionar la declaración de la Corte Interamericana de Derechos Humanos (CIDH, 2020), intitulada Covid-19 y Derechos Humanos. Los problemas y desafíos deben ser abordados con perspectiva de Derechos Humanos y respetando las obligaciones internacionales, en la cual indica que,

dada la naturaleza de la pandemia, los derechos económicos, sociales, culturales y ambientales deben ser garantizados sin discriminación a toda persona bajo la jurisdicción del Estado y, en especial, aquellos grupos que son afectados de forma desproporcionada, porque se encuentran en situación de mayor vulnerabilidad.

Acá se parte de la advertencia de la protección de los derechos económicos, sociales, culturales y ambientales (Desca) y, en el caso que nos ocupa, el derecho humano al agua potable, al saneamiento y también a la vivienda digna.

La Organización Mundial de la Salud (oms, 2005), ente necesariamente referenciado en este trabajo, dentro de sus directrices para mitigar el impacto del covid-19 presenta el hábito del lavado de manos: "Es la medida primordial para reducir dichas infecciones. Aunque se trata de una acción sencilla, su incumplimiento entre los dispensadores de atención sanitaria representa un problema en todo el mundo" (p. 12). Esta medida que parece simple, no lo es en diversas regiones del mundo, así también para algunas regiones de Colombia, donde la escasez del servicio de acueducto es innegable. Ello, además, evidencia la importancia de garantizar el derecho al mínimo vital a las comunidades vulnerables, como el derecho al agua potable y el cuidado de la salud, ya que las medidas de control de la pandemia implican mayor uso del agua en el lavado de las manos y desinfección en general.

Lo anterior cobra más sentido si se tiene en cuenta que, según la oms (2017), millones de personas carecen de instalaciones sanitarias: "En todo el mundo, alrededor de tres de cada diez personas, 
o 2100 millones de personas, carecen de acceso a agua potable y disponible en el hogar, y seis de cada diez, o 4500 millones, carecen de un saneamiento seguro". Colombia no es ajena a esta problemática.

Bajo el modelo institucional de los SPD, en Colombia, se encuentran dentro de la estructura organizacional del Estado, las Comisiones de Regulación; las cuales, conforme con lo dispuesto en el artículo 365 de la Carta Política y la ley, tienen la facultad de la regulación en virtud del artículo 68 de la Ley 142 de 1994.

Estas comisiones ejercen funciones encomendadas al presidente de la República, "quien, mediante delegación, les atribuye a las citadas entidades las políticas generales de eficiencia y administración de los SPD" (Bustos, 2016, p. 37). Estas agencias, que se encuentran dentro de la denominada administración pública económica, permiten que el Estado intervenga en la economía (Bustos, 2016). Por ello y en caso de la declaratoria de Estado de Emergencia Económica, Social y Ecológica en el territorio nacional, estos entes han sido llamados a proferir resoluciones o directrices esenciales, con el fin de regular el impacto de las medidas o de las situaciones que dieron origen a la declaratoria del estado de excepción.

Uno de los actos analizados aquí son las resoluciones de la Comisión de Regulación de Agua Potable y Saneamiento Básico (CRA), emitidas en el marco de este estado de excepción; y la explicación de los sustentos de ley que permiten o justifican las medidas. La primera es la Resolución -UAE CRA no. 178 de 2020, "Por la cual se adoptan medidas para garantizar la atención y la prestación de los servicios por parte de la Unidad Administrativa de la Comisión de Regulación de Agua Potable y Saneamiento Básico, en el marco de lo dispuesto en el Decreto Legislativo 491 de 2020", del Ministerio de Vivienda, Ciudad y Territorio de Colombia, expedida el 01 de abril de 2020; ministerio al que se adscribe la CRA.

También haremos una revisión de decretos que profirió este ministerio, ya que este es el ente rector de la política de Estado en materia de acueducto y saneamiento básico.
En un momento de emergencia como el que se está estudiando y ante un modelo de prestación de los SPD como el colombiano, era necesario contar con medidas que permitieran a los operadores de servicios públicos (sin importar su naturaleza) exonerar y condonar pagos de facturas. Bien es sabido que las empresas de servicios públicos y los operadores en general no están facultados, en ninguna circunstancia, de eximir a nadie del pago de los servicios públicos domiciliarios; tampoco pueden, salvo disposición de la regulación, condonar deudas o diferir pagos.

Por ello, el Decreto presidencial 580 de 2020 se pronunció sobre los subsidios a los SPD, haciendo la salvedad de que no se constituye en una medida novedosa por la pandemia, sino que se hace un aumento del subsidio o beneficio, debido a la crisis ${ }^{4}$.

Asimismo, para garantizar los servicios públicos, bien sea por las empresas estatales, las entidades territoriales o las empresas con capital privado, el Estado será garante del pago de los subsidios, tal como lo prevé el artículo del decreto citado 5 .

4 El Decreto 580 de 2020 dice: "Subsidios para los servicios de acueducto, alcantarillado y aseo. Hasta el 31 de diciembre de 2020, los municipios y distritos podrán asignar a favor de los suscriptores residenciales de los servicios de acueducto, alcantarillado y aseo, subsidios máximos del ochenta por ciento (80\%) del costo del suministro para el estrato 1 ; cincuenta por ciento $(50 \%)$ para el estrato 2; y cuarenta por ciento $(40 \%)$ para el estrato 3 [...]. Los concejos municipales deberán expedir, a iniciativa del respectivo alcalde municipal o distrital, los respectivos acuerdos transitorios que implementen esta medida. En estos casos, las administraciones municipales deberán tener en cuenta las medidas de aislamiento [...] y realizar las reuniones virtuales necesarias para viabilizar estas modificaciones. Adicionalmente, deberán atender las condiciones para otorgar subsidios establecidos en la Ley 142 de 1994 y deberán realizar auditoría a las facturas por déficit de subsidios presentados por los prestadores” (art. 1).

5 "Pago de servicios públicos de acueducto, alcantarillado y aseo por entidades territoriales. Hasta el 31 de diciembre de 2020, las entidades territoriales podrán asumir total o parcialmente el costo de 
En la medida que el numeral 6 del art 99 de la Ley de 1994, establece que

la parte de la tarifa que refleje los costos de administración, operación y mantenimiento a que dé lugar el suministro será cubierta siempre por el usuario; la que tenga el propósito de recuperar el valor de las inversiones hechas para prestar el servicio podrá ser cubierta por los subsidios y, siempre que no lo sean, la empresa de servicios públicos podrá tomar todas las medidas necesarias para que los usuarios las cubran. En ningún caso el subsidio será superior al $15 \%$ del costo medio del suministro para el estrato 3, al $40 \%$ del costo medio del suministro para el estrato 2, ni superior al $50 \%$ de este para el estrato 1.

Por ello, era necesario crear una disposición para incrementar transitoriamente los porcentajes máximos subsidiados, como previó el decreto estudiado. Lo importante del intento es verificar si, como se ha manifestado, esto puede revisarse para que se amplíe la base o los porcentajes que tiene la ley, y que los decretos modificaron por la pandemia.

Lo anterior tiene sustento en la Constitución y en el artículo 99 de la Ley 142 de 1994, que explica la política de subsidios para la población vulnera$b^{6}{ }^{6}$. Pero, por motivo de la pandemia, los que se

los servicios públicos de acueducto, alcantarillado y aseo de los usuarios, teniendo en cuenta [...] la necesidad de priorizar las asignaciones para las personas de menores ingresos. En aquellos casos en que las entidades territoriales decidan asumir total o parcialmente el costo de los servicios públicos de acueducto, alcantarillado y aseo, dichas entidades deberán girar a las personas prestadoras la parte correspondiente de la tarifa que haya sido asumida por el ente territorial respectivo [...]. Las administraciones municipales podrán verificar la base de usuarios para no realizar pagos sobre predios inexistentes, predios duplicados, predios urbanizados no construidos y consumos suntuarios” (Decreto 580, 2020, art. 2).

6 "Las entidades señaladas en el artículo 368 de la Constitución podrán conceder subsidios en sus respectivos presupuestos de acuerdo [con] las siguientes reglas: Deben indicar específicamen- han venido otorgando resultan insuficientes para cubrir las necesidades de la población y para cumplir con las medidas sanitarias de la oms.

Del mismo modo, en virtud de la declaratoria de emergencia, el Ministerio de Vivienda expidió la Resolución CRA 911 de 2020, "Por la cual se establecen medidas regulatorias transitorias en el sector de agua potable y saneamiento básico, derivadas de la emergencia declarada por el Gobierno Nacional a raíz del Covid-19". Esta resolución buscaba que las empresas y operadores procedieran de manera inmediata a reconectar los servicios públicos y no pudieran interrumpir el servicio, ya que impedirían la posibilidad de las normas de higienes necesarias para evitar la propagación del virus.

Lo expuesto no solo tiene soporte en las funciones de las comisiones de regulación, sino en el caso específico de lo previsto en la Ley 142 de 1994:

El incumplimiento del contrato por parte del suscriptor o usuario da lugar a la suspensión del servicio en los eventos señalados en las condiciones uniformes del contrato de servicios y en todo caso en los siguientes:

La falta de pago por el término que fije la entidad prestadora, sin exceder en todo caso de dos (2) períodos de facturación en el evento en que esta sea

te el tipo de servicio subsidiado. Se señalará la entidad prestadora que repartirá el subsidio. El reparto debe hacerse entre los usuarios como un descuento en el valor de la factura que este debe cancelar, conforme a lo dispuesto en esta ley [...]. El presidente y los gobernadores podrán suspender a los alcaldes cuando sean negligentes en la aplicación de las normas relativas al pago de los subsidios [...]. Los subsidios no excederán, en ningún caso, del valor de los consumos básicos o de subsistencia. Los alcaldes y los concejales tomarán las medidas que a cada uno correspondan para crear en el presupuesto municipal, y ejecutar, apropiaciones para subsidiar los consumos básicos de acueducto [y saneamiento básico] de los usuarios de menores recursos [...]. La parte de la tarifa que refleje los costos de administración, operación y mantenimiento a que dé lugar el suministro, será cubierta siempre por el usuario” (Ley 142, 1994, art. 99). 
bimestral y de tres (3) períodos cuando sea mensual $y$ el fraude a las conexiones, acometidas, medidores o líneas. (art. 140)

En este caso, los decretos emanados de la emergencia facultaron al Estado para cubrir las deudas de los usuarios morosos y ser garantes ante las empresas y operadores de los beneficios mientras durara la crisis; los cuales se respaldaron por el Estado colombiano como subsidio a la demanda ${ }^{7}$.

Estas medidas económicas buscaban la exoneración del pago de servicios públicos a las familias más vulnerables, de conformidad con los acontecimientos, la calamidad y los problemas de salubridad que requieren de la disponibilidad de los SPD, todo también para garantizar el mínimo vital y el Derecho Humano al agua potable.

Luego, como prevé la Constitución en el parágrafo del artículo 215, la Corte Constitucional empezó a estudiar los decretos derivados de las medidas tomadas, debido a la declaratoria de emergencia, de acuerdo con el numeral 07 del artículo 241 de la Constitución ${ }^{8}$. Como consecuencia,

7 Cuando un prestador “de los servicios públicos de acueducto, alcantarillado y/o aseo requiera la constitución de garantías, podrá utilizar para el efecto, entre otras, las siguientes: (1) la cesión de la porción no subsidiada de las cuentas por cobrar o facturas debidas por los usuarios de cualquier estrato; (2) los subsidios causados o que vaya a recibir por la prestación del servicio; (3) cualquier otro tipo de garantía suficiente para la entidad financiera, multilateral o bilateral que ofrezca la línea de liquidez" (Decreto 528, 2020, art. 2, parágrafo). En el mismo artículo se resalta a su vez: "Las empresas de servicios públicos oficiales o mixtas a las que se refiere este artículo, quedarán exentas del cumplimiento de los límites de endeudamiento estatal fijados”.

8 El artículo 241 de la Constitución establece que a "la Corte Constitucional se le confía la guarda de la integridad y supremacía de la Constitución, en los estrictos y precisos términos de este artículo. Con tal fin, cumplirá las siguientes funciones [...]: No. 7. Decidir definitivamente sobre la constitucionalidad de los decretos legislativos que dicte el Gobierno con fundamento en los artículos 212, 213 y 215 de la Constitución”. la Corte Constitucional se pronunció sobre la exequibilidad de los decretos relacionados con los servicios públicos domiciliarios, que fue necesario expedir para afrontar la pandemia.

En cuanto a los SPD, la Corte Constitucional se pronunció en la Sentencia C-154 de 2020, sobre la exequibilidad del Decreto 441 de 2020, que buscó la reconexión inmediata de todos los usuarios que por falta de pago tuvieran suspendido el servicio. En este caso concreto, declaró exequible el Decreto, salvo su artículo primero, en relación con la expresión "con excepción de aquellos suspendidos por fraude a la conexión o al servicio". Este decreto, vino a convertirse en una medida importante, ya que con ella se intentó materializar y garantizar el derecho humano al agua potable que, en tiempos de pandemia y por su relación de la higiene, mitiga las consecuencias del virus y evita cualquier tipo de exclusión y discriminación de usuarios frente a un derecho humano.

De otra parte, aunque estemos ante situaciones sobrevinientes y no previsibles, los decretos, también como establecen la Carta y la ley ${ }^{9}$, pasan al control inmediato de legalidad por parte del Consejo de Estado. Esta función constituye "una limitación al poder de las autoridades administrativas y es una medida eficaz para impedir la aplicación de normas ilegales en el marco de los estados de excepción" (Almanza y Pérez, 2020, p. 380), lo cual viene a materializar el control y el equilibrio entre las ramas del poder público en Colombia.

Para el caso que nos ocupa, en relación con las medidas de emergencia del Gobierno nacional y entidades como la Comisión de Regulación de Agua Potable, el Consejo de Estado también

9 El artículo 20 de la Ley 137 de 1994 contempla que "las medidas de carácter general que sean dictadas en ejercicio de la función administrativa y como desarrollo de los decretos legislativos durante los estados de excepción, tendrán un control inmediato de legalidad, ejercido por la autoridad de lo contencioso administrativo [...]. Las autoridades competentes que los expidan enviarán los actos administrativos a la jurisdicción contenciosoadministrativa indicada, dentro de las cuarenta y ocho (48) horas siguientes a su expedición”. 
asumió el conocimiento de los actos administrativos proferidos en virtud de la emergencia.

\section{Sectores afectados}

El tema de cobertura, calidad y continuidad de los servicios públicos, en especial, de agua y saneamiento básico, ha sido preocupante especialmente para el sector rural. Existe una asimetría en todos los sentidos, debido a que los municipios menores, de sexta categoría, que constituyen el $87,9 \%$ del total dependen de las transferencias de la nación para atender todas las obligaciones que como entidad territorial le corresponden (Delgado et al., 2020, p. 139) ${ }^{10}$. En estos lugares la cobertura de servicios es baja o nula. Donde hay infraestructura, la frecuencia y continuidad del servicio es de mala calidad, por la escasa capacidad del ente para administrar con los criterios de sostenibilidad las infraestructuras entregadas por el Estado central o el departamento al que pertenecen.

Estos municipios, clasificados por la ley en sexta categoría, son en parte la realidad más inquietante en este proceso. Ello contrasta con los centros poblados en ciudades capitales o en áreas metropolitanas, que sí cuentan con la infraestructura para garantizar el servicio de agua potable. Si se revisan las cifras, las capitales han sabido sortear, con la infraestructura y las medidas extraordinarias, el impacto de la pandemia.

10 "Para el caso de los municipios, especialmente los más pequeños presupuestalmente hablando, las fuentes de las cuales derivaban los recursos para atender las responsabilidades asumidas por el proceso descentralizador, comprendían los recursos propios, provenientes de una estructura predial soportada por un catastro desactualizado, unas actividades comerciales, industriales y de servicios incipientes o pequeñas en sus territorios y el consumo de combustibles, los cuales oscilan alrededor del $10 \%$ de los ingresos municipales totales, quedando el resto del financiamiento a cargo de los recursos de deuda y los provenientes de las transferencias del nivel nacional o departamental (sGP, regalías, fondos especiales, etc.), lo que los dejó con un alto nivel de dependencia fiscal” (Delgado et al., 2020, p. 139).
En Colombia, el área rural tiene una cobertura de acueducto alrededor del $73 \%$ (Carrasco, 2015). Esto lleva a que un buen porcentaje de la población no pueda lavarse las manos con la frecuencia que recomienda la oms. Se suma a esa problemática la falta de información y acompañamiento que el Estado tiene sobre los entes comunitarios para la prestación de los servicios públicos. Por ejemplo, "cerca de 20 mil organizaciones comunitarias y sin ánimo de lucro que prestan servicios de agua y saneamiento en el área rural del país, carecen de autorización legal para suministrar estos servicios" (Carrasco, 2015, p. 51).

Adicionalmente, "tampoco existe información actualizada de los prestadores de agua y saneamiento, ni de la calidad de los servicios con que cuenta la población rural en el país. Menos del $2 \%$ de las muestras que toman las autoridades sanitarias para vigilar la calidad del agua en el país, son tomadas en áreas rurales" (Carrasco, 2015, p. 51).

De esta manera, debe ser un compromiso del Estado colombiano y, a la vez, un desafío inmediato, la construcción de acueductos no convencionales, para adaptarse a las realidades del país. Igualmente constituye un reto la responsabilidad que implica garantizar el acceso de agua potable y saneamiento, no solo para superar o mitigar el Covid-19, sino todo tipo de enfermedades o procesos endémicos que seguirán conviviendo en la nación.

No suspender el servicio ha sido una de las más importantes medidas que identificó el Gobierno para lograr que los habitantes del país pudieran acatar las medidas sanitarias de la oms, en relación con el lavado de manos. También se decidió reconectar a todo usuario que no contara con el servicio por falta de pago. Es innegable que, en Colombia, como en todos los países en vía de desarrollo, "la mayoría de los que no tienen acceso a agua potable y saneamiento son personas pobres de zonas tanto urbanas como rurales" (ONU, 2018, p. 19). Esta medida también se suma a garantizar el Derecho Humano al agua potable.

Es evidente que, en Colombia, falta ajustar con estudios y lineamientos concretos lo que "sigue" luego de superada la crisis. Es necesario conocer lo que pasará con las personas de menores ingresos 
que viven en zonas rurales, a fin de que no se vean en "situaciones lamentables donde tiene que recoger agua de fuentes no protegidas, como pozos o canales de riego contaminados, o comprarla a un precio más alto que el que pagan las personas conectadas al sistema de agua corriente" (ONU, 2018, p. 20). Esta medida no solo fue tomada en Colombia, si no en varios países del mundo.

El Banco Interamericano de Desarrollo (BID, 2020), por ejemplo, refiriéndose al impacto del Covid-19 en América Latina, menciona que también la crisis generó impactos importantes en la demanda de electricidad y agua:

Si bien la demanda domiciliaria subió, la demanda industrial y comercial cayó aún más por las restricciones inducidas a la producción. El impacto en los ingresos de las empresas proveedoras ha sido aún mayor por la estructura de tarifas, que son más bajas para los hogares. La decisión de muchos Gobiernos de permitir que los hogares no paguen las facturas y de prohibir la desconexión de los servicios causan a las empresas proveedoras de servicios problemas financieros adicionales. (p. 30)

En Colombia, el tema de las empresas prestadoras de servicios es diferente, ya que, en el país, tal como se había mencionado, no existe "privatización" (propiedad de los activos e infraestructura por parte de particulares), sino una coparticipación del sector privado en los servicios de agua potable y saneamiento básico. Las empresas del sector privado que cuentan con participación lo hacen como contratistas o gestores, lo cual compromete al Estado, como efectivamente se evidencia en la norma en cuestión. Asimismo, la política de subsidios hace que estas empresas tengan garantizados sus ingresos para seguir operando.

Volviendo al sector rural, hay que recordar que Colombia tiene "una larga tradición de gestión comunitaria de los servicios de agua en zonas rurales", pues "desde finales de la década de 1960 las comunidades rurales tomaron bajo su responsabilidad la prestación de los servicios de agua y saneamiento, obteniendo diversos resultados en cuanto a eficiencia y efectividad de los servicios brindados" (BID, 2012, p. 10).
De la mano de los acontecimientos y viendo que la pandemia invita al distanciamiento social, es posible que el sector rural o urbano menor termine siendo afectado, en la medida en que las personas intenten migrar a sitios menos poblados, donde se pueda vivir en espacios abiertos, con menos aglomeración. Es posible que, a futuro, la política pública invite a invertir y a fortalecer estos centros poblados.

\section{Desafíos para el sector rural}

La realidad del sector rural y veredal es particular. La emergencia, entendida no como el estado de excepción, sino como el fenómeno de calamidad de orden mundial, hará (y es una hipótesis) que el sector rural o el urbano menor adquiera una preponderancia no prevista, en la medida que el aislamiento social y la búsqueda de espacios abiertos y no conglomerados o multifamiliares permitirán que este sector, por años rezagado, pueda ser reivindicado con más inversiones en servicios públicos domiciliarios y otros que no se han mencionado aquí.

En el imaginario común, los usuarios de los servicios públicos son los que viven en las grandes ciudades. De hecho, existen quienes cuentan con conexiones domiciliarias y reciben una facturación y están conectados a acueductos convencionales. Sin embargo, el rural es el sector de mayor rezago, hacia el cual debe apuntar la política pública de inversión y también de diseño de un marco institucional.

Recientemente, el Gobierno nacional estableció para el sector rural, según el Ministerio de Vivienda, Ciudad y Territorio (Minvivienda), un "subsidio que cubre hasta $\$ 12400$ pesos mensuales por suscriptor, o vivienda conectada, pero es de aclarar, que este valor no se entrega a las familias, sino que es un descuento que aplica el prestador a la tarifa mensual de agua a pagar por estas familias" (Minvivienda, 2020b).

Según el Gobierno Nacional, las asociaciones comunitarias y las juntas administradoras de los acueductos rurales son las que recibirán los recursos del Estado, los cuales se distribuirán entre 
el número de usuarios que dichos entes tengan registrados.

\section{Usuarios sector industrial y comercial}

La otra cara de la moneda, desde las mismas empresas de servicios públicos, es la disminución del consumo en el sector comercial e industrial. Miremos lo que pasa, por ejemplo, en una empresa de energía: "Los edificios de oficinas cerrados y las pequeñas empresas significan menos kilovatios-hora vendidos" (Kavulla y de la Fuente, 2020). Si se ha leído lo anterior, se pensaría que no debería ser un problema, ya que no hay consumo y el Estado de alguna manera subsidia a los de menores ingresos y hace descuentos a los demás usuarios, tal como lo expresan las normas transitorias analizadas.

La dificultad radica en que el sector industrial y comercial en Colombia - así como los usuarios de mayores ingresos - contribuyen con un sobreprecio para subsidiar a los de menores ingresos ${ }^{11}$. Esta fuente del sector industrial y comercial ha disminuido, por lo que el Estado tiene que hacer un mayor esfuerzo para trasladar a las empresas (de cualquier naturaleza) ese sobreprecio. De la misma forma, el sobreprecio para los estratos altos se ha incrementado, pero no llegan a compensar los aportes del sector productivo. Ello puede afectar a los usuarios residenciales que, aunque tengan mayores ingresos, no todos pudieron haber salido favorecidos de las crisis, es decir, aquellos empresarios afectados por la recesión o profesionales que perdieron sus empleos.

11 El artículo 89 de la Ley 142 de 1994 autoriza los aportes solidarios de los estratos residenciales 5 y 6 y el sector industrial y comercial, para aliviar las facturas de los usuarios de menores ingresos: "Se presume que el factor aludido nunca podrá ser superior al equivalente del $20 \%$ del valor del servicio [...]. Cuando comiencen a aplicarse las fórmulas tarifarias de que trata esta Ley, las comisiones solo permitirán que el factor o factores que se han venido cobrando, se incluyan en las facturas de usuarios de inmuebles residenciales de los estratos 5 y 6 , y en las de los usuarios industriales y comerciales”.
Este proceso debe replantear la política tarifaria y de subsidios, ya que los fondos de solidaridad y las empresas quedan sin un importante recurso de sobreprecio del sector industrial y comercial para el sector de los servicios públicos. De igual forma, el teletrabajo y la virtualidad en educación generan mayor consumo residencial de servicios públicos domiciliarios, y van a impactar en los sobreprecios de los sectores que, por ley, deben contribuir.

El Decreto 580 de 2020 del Ministerio de Vivienda, Ciudad y Territorio, como complemento de lo previsto en la Resolución CRA 911 de 2020, se pronunció sobre los subsidios que el Estado otorgaría (en mayor medida) a los usuarios de las poblaciones vulnerables. Por tal razón, el decreto estableció:

Subsidios para los servicios de acueducto, alcantarillado y aseo. Hasta el 31 de diciembre de 2020, los municipios y distritos podrán asignar a favor de los suscriptores residenciales de los servicios de acueducto, alcantarillado y aseo, subsidios máximos del ochenta por ciento ( $80 \%$ del costo del suministro para el estrato 1 ; cincuenta por ciento $(50 \%)$ para el estrato 2; y cuarenta por ciento (40\%) para el estrato 3 , en la medida en que cuenten con recursos para dicho propósito. Para el efecto, los concejos municipales deberán expedir, a iniciativa del respectivo alcalde municipal o distrital, los respectivos acuerdos transitorios que implementen esta medida. (art. 1)

Mientras que la Resolución de la Comisión de Regulación se manifestó sobre la conexión, el decreto se pronunció sobre los subsidios y sus fuentes de financiación. Por ello, el decreto estableció que los concejos municipales pueden expedir acuerdos transitorios, a iniciativa del alcalde, para implementar esta medida, ya que implica disposición de recursos estatales para subsidios. Cuando se aprueben subsidios adicionales ${ }^{12}$ para estos subsidios y

las entidades territoriales decidan asumir total o parcialmente el costo de los servicios públicos de acueducto, alcantarillado y aseo, dichas entidades

12 Son adicionales, ya que por ley los usuarios de menores ingresos reciben subsidios o mínimo vital gratuito para los consumos de subsistencia. 
deberán girar a las personas prestadoras la parte correspondiente de la tarifa que haya sido asumida por el ente territorial respectivo, por cada uno de los suscriptores o usuarios beneficiarios de la medida, y suscribirán los actos o contratos que se requieran a tal efecto. (Decreto 580, 2020, art. 2)

Como se ve, las medidas están orientadas a no desconcertar a ningún usuario, garantizar la cobertura y calidad de los servicios y brindar alivios a los usuarios, para no hacer más gravosa la situación en medio del aislamiento, al otorgar beneficios para el pago diferido de las facturas a los distintos tipos de usuarios. Se observa también que las medidas de las disposiciones son transitorias, es decir, hasta el 31 de diciembre de 2020. Sin embargo, como se ha planteado en el inicio del trabajo, muchas pasarán a ser revisadas para convertirse en definitivas, con el debido análisis de viabilidad financiera y ambiental, así como se expone en las reflexiones finales de este trabajo.

Por otra parte, el 01 de abril de 2020, el Ministerio de Vivienda, Ciudad y Territorio dispuso que las empresas de servicios públicos domiciliarios, sin importar su naturaleza, quedarían

exentas del cumplimiento de los límites de endeudamiento estatal, fijados por las normas aplicables. En todo caso, deberán cumplir las autorizaciones de endeudamiento contenidas en el artículo 2.2.1.2.2.3 del Decreto 1068 de 2015, adicionado por el Decreto 473 de 2020.

Ello indica que, a través del Ministerio de Hacienda y Crédito Público, el Estado genera también excepciones para que dichos entes, que son autónomos, puedan tener salud financiera, pese a la crisis.

\section{Esfuerzos estatales}

Hasta el 31 de diciembre de 2020, los municipios y distritos pudieron asignar, a favor de los suscriptores residenciales de los servicios de acueducto, alcantarillado y aseo, subsidios máximos del $80 \%$ del costo del suministro para el estrato 1; $50 \%$, para el estrato 2; y $40 \%$ para los servicios de acueducto, alcantarillado y aseo. Adicional a ello, el Estado ha contemplado que la [CRA] deberá expedir la regulación general que se requiera para implementar las medidas contenidas en los decretos legislativos expedidos para el sector de agua potable y saneamiento básico en el marco de la Emergencia Económica, Social y Ecológica, contenidas en los Decretos 441 y 528 de 2020 y en el presente decreto, así como adoptar de manera transitoria esquemas especiales para diferir el pago de facturas emitidas, y adoptar de manera transitoria todas aquellas medidas, disposiciones tarifarias y regímenes regulatorios especiales que considere necesarios. (CRA, Concepto 61871, 2020)

Al finalizar la pandemia, el escenario financiero de esas empresas va a ser delicado y el Gobierno nacional deberá pensar en brindar la salida para que los servicios sean prestados con eficiencia. El sector financiero tampoco podrá asumir en solitario la carga de financiar las empresas hasta su recuperación, a muchas de las cuales no les será posible recuperarse con el ejercicio de su actividad, cuyo servicio se ofrece a un mercado golpeado en sus posibilidades reales de ingresos.

Será necesario analizar hasta qué punto las medidas de salvamento adoptadas por el Gobierno - vía subsidios a los usuarios representados en giros directos a los operadores públicos, privados, mixtos o comunitarios - permiten asumir todos los costos en los que debió incurrir para garantizar el acceso al universo de la población. Para nadie es un secreto que las bases de datos para poder cuantificar esos beneficios (atados a estudios de estratificación) no deben estar acorde con la real situación de la demanda. Pero no es menos cierto que la producción de agua potable no llega en su totalidad a los usuarios, por todas las ineficiencias que generan los procesos de pérdidas físicas; es decir, en las redes, por su obsolescencia. Tampoco es desconocido que existen grandes porcentajes de agua no contabilizada por pérdidas comerciales de usuarios clandestinos, que también se constituyen en un factor preocupante.

En resumen y como propuesta, la manera de intentar garantizar una mayor cobertura sería incrementar la producción, la cual no podrá soportar en su entrega mediante una controlada macro- y micromedición, y ajustes a los contratos de operación y gestión existentes entre las empresas y el 
Estado (municipios y distritos). Estos costos de la ineficiencia serán reclamados al ente territorial o al Estado tarde o temprano, o producirán pérdida financiera de una proporción tan alta que sacarán del mercado a las empresas ante la incapacidad de cumplir sus obligaciones con las entidades que los financiaron para lograr esa producción.

\section{Desafíos y oportunidades}

El aislamiento, como medida para garantizar o preservar el derecho a la salud, invita a pensar en otros derechos que permiten o permitirían la posibilidad de confinamiento con garantías. Tal es el caso del acceso o la disponibilidad de los servicios públicos domiciliarios, atado a esto al concepto de vivienda digna, derecho cuya garantía y calidad debe revisarse su desarrollo a futuro en beneficio de los menos favorecidos, por la vivencia que se ha experimentado durante el confinamiento.

Si bien las medidas tomadas por el Estado fueron acertadas y acordes con las circunstancias y los recursos existentes en el fisco nacional y territorial, quedan aún por afinar la garantía de otros derechos, como el de la vivienda digna ${ }^{13}$. La situación puso al descubierto lo que la CIDH menciona en relación con otros derechos. En este caso, el "acceso al agua potable y el saneamiento se relaciona con todas y cada una de las actividades y las necesidades del ser humano, un elemento vital sin el cual simplemente no se puede sobrevivir, menos, vivir dignamente" (Becerra y Salas, 2016 p. 129).

También quedó en evidencia que el Estado está en capacidad de seguir garantizando los servicios públicos domiciliarios y el derecho humano al agua potable, el cual debe verse - y esta es una postura que poco se analiza- desde dos dimensiones: una, como recurso natural necesario para todos los seres vivos de este planeta y, en el caso específico, el territorio nacional; la otra "es proteger las agua bajo criterios de regulación en cuanto

13 Una vivienda inadecuada puede tener repercusiones en el derecho a la salud. Por ejemplo, si las viviendas no cuentan con suficiente agua potable y saneamiento, sus residentes pueden enfermarse de gravedad (oNU-Hábitat, 2010). a su cantidad (uso racional) y en cuanto a su calidad (mantenimiento de las condiciones naturales) y cuya contaminación y deterioro debe asimismo prevenirse y controlarse" (Nava-Escudero, 2018, p. 76). De la misma manera, debe percibirse como el derecho al mínimo vital.

Si bien en varios escritos hemos propuesto reflexionar sobre el cambio de política (Echeverría 2014, 2015; Echeverría y Anaya, 2018), esta pandemia y sus decretos de emergencia aceleran el proceso para generar tal trasformación. Por ello, se insiste en que lo novedoso de lo vivido es lo poco escalonado que invita a apresurar los cambios que se requieren.

El mínimo vital gratuito es una política pública que se viene implementando en distintas ciudades, para que las personas de menores ingresos puedan tener agua potable. Esta crisis puede favorecer para que se trabaje como política pública generalizada y constante, a fin de incluirlo en los programas de las entidades territoriales. Entretanto, debe cuidarse de que existan controles, debido a que el excesivo consumo entra a afectar el Derecho Humano al agua como recurso y también el mínimo vital del servicio; es decir, cuando se requiere para proteger la subsistencia de otras personas (es un derecho humano) en condiciones de vulnerabilidad.

En este sentido, en su jurisprudencia, la Corte Constitucional colombiana "ha tutelado el derecho al agua como fundamental por su conexidad con el derecho a la vida que se refiere a la dignidad humana e implica un mínimo de subsistencia. En este caso, el acceso a un mínimo de agua, y precisamente por ese carácter social solo ha sido tutelado a personas especialmente protegidas" (Restrepo y Zárate, 2016, p. 128). Se debe dar profundidad en esa línea delgada entre Derecho Humano al agua (como recurso) y mínimo vital gratuito, como derecho a un recurso de subsistencia, que depende del uso racional y de que exista el recurso.

Sabemos que esto debe ir de la mano de un fuerte componente comunitario, para evitar altos consumos y desperdicios. Se tiene la experiencia en los sitios donde se implantó la medida de la gratuidad, donde el beneficio generó el efecto predecible y pudo verificarse por parte del Estado que "el impacto del mínimo vital, en Bogotá los hogares 
que fueron influenciados con esa medida subieron los consumos más que los del resto de municipios de tierra fría” (Ocampo-Rodríguez, 2018), situación que, como se ha explicado, afecta el derecho de otros y el derecho humano al agua.

En el caso anterior, debe tenerse en cuenta la diversidad geográfica y cultural del país, en la medida en que el consumo de agua es determinado por variables como

factor climático (temperatura, precipitación pluvial, humedad relativa), factor social (habitantes por vivienda, composición familiar, nivel de educación, estrato social), factor económico (ingreso familiar, precio del agua, consumo histórico) y factor cultural (estilo de vida de las personas, valores, normas y modelos sociales, creencias asociadas a la conducta ambiental) que, de acuerdo con el contexto, tendrán diferentes relevancias. (Manco et al., 2012, p. 25)

Esta acotación es necesaria dentro del diseño de la política. Entretanto, cuando las personas expresan recibir con agrado una política de gratuidad a un mínimo de agua, muchos sustentan la solución frente al imaginario de que Colombia es potencia hídrica. Lamentablemente, el argumento, por demás generalizado, es peligroso. En la medida en que esto no vaya de la mano de un control estricto de consumo y una política de sobreprecio al despilfarro, el supuesto de potencia hídrica desaparece, ya que hemos ido perdiendo esa calidad.

Asimismo, siendo paradójico en este momento, Colombia, bajo el entendido de que es una "potencia” hídrica, puede usar a libre demanda el recurso, por lo cual a veces resulta retador para el Estado imponer restricciones cuando se vende la idea de la libre demanda, la gratuidad y el derecho infinito.

De esta manera y ante un panorama hídrico inquietante,

los medios han señalado en repetidas ocasiones que el agua es cada vez más escasa, al parecer, aún no se toma conciencia del problema, pues las personas, cuando abren el grifo, no toman en cuenta lo escaso del recurso ni lo que cuesta, o todo lo que implica abastecer a las ciudades. Solo se tiene noción de lo importante que es el agua cuando por alguna causa el servicio de abastecimiento se suspende. (Esparza, 2014, p. 197)

Es el momento de reflexionar y verificar esa línea casi imaginaria en el derecho humano al agua. Un asunto es que el Estado cuide las fuentes de agua, las descontamine, reforeste, no permita que se sequen los humedales, que nadie construya sobre ellos o que no se desequen las lagunas; otro muy diferente es que se hable del mínimo vital gratuito de agua potable, es decir, agua procesada, agua que ha sido transformada para el consumo humano y para necesidad básicas y esenciales.

La sensación de escasez de agua se percibe más en el área rural; pero en las grandes ciudades o en centros urbanos con un sistema de acueducto apropiado es más complejo de detectar esta situación. Por ejemplo,

un episodio de sequía puede estar presente en una población y la sociedad no la percibiría, si se cuenta con el agua suficiente en sus embalses para abastecer el consumo habitual de la población hasta el regreso de las lluvias. Esto puede ser posible, si dicha población se surte por medio del trasvase de agua de una cuenca lejana donde la sequía no esté golpeando. (Esparza, 2014, p. 199)

Lo anterior es lo que se percibe en el sector urbano, conectado a un acueducto convencional, el cual solo notará la escasez en caso de racionamiento o de apagones, por disminución de la capacidad de los embalses.

También sería conveniente, después de todo proceso, monitorear las aguas servidas para verificar que en ellas no se desechen o existan restos de la existencia de riesgo de virus; no solo Covid-19, sino todos tipos de bacterias y patógenos que puedan estar presentes en las aguas residuales.

Adicionalmente, nada indica que, a futuro, otros virus, bacterias o gérmenes que afecten la salud humana no sean transmitidos por el agua o en el agua residual. De ese modo, la tarea es constante. Y, aunque parece una decisión impropia para muchos, los consumos deben pagarse si sobrepasan el mínimo de subsistencia. Si bien parece no ser consecuente con la crisis, sí lo es con el medioambiente. 


\section{Conclusiones}

El covid-19 evidenció que es posible hacer cambios en la política pública de servicios públicos, en el caso de los servicios de agua potable y saneamiento básico. También consiguió que las personas empezaran a hacer una asociación que hace tiempo se estaba necesitando: la relación entre el consumo con el precio de los servicios, ya que no todos los usuarios eran conscientes de esa relación y, probablemente, pensarían en la asignación fija o constante de un valor para libre demanda. Igualmente, puso de relieve que hay recursos del Estado para atender en mayor medida a los usuarios de menores ingresos y que las medidas pueden materializarse cuando el Gobierno es el garante de los recursos frente a los operadores. El problema radica en si es sostenible para el medioambiente y financieramente.

Es momento de analizar y trazar nuevas estrategias, ya que es una oportunidad para dejar en el imaginario de las personas y del Estado la importancia del recurso y su fragilidad ante el uso desmedido y su contaminación. Si se dispone de agua y saneamiento no combatiremos los virus, pero sí puede afrontarse tal situación con más responsabilidad y con mejores resultados para las medidas básicas de higiene.

Lo vivido en el marco de la pandemia invita al Congreso de la República a trabajar en reformas de la ley, ya que el Sistema General de Participaciones, que constituye una camisa restrictiva para hacer inversiones por fuera del parámetro de esta ley debe cambiar sus porcentajes, para que se asigne de preferencia en financiar el mínimo vital gratuito a todos los habitantes del territorio nacional. Ello generará, a la vez, una política de incentivo al ahorro. Lamentablemente, este aspecto es poco conocido por los juristas y más bien pertenece a la órbita de los abogados expertos en finanzas territoriales, lo que hace enorme la labor con recursos limitados (por la ley); rigideces que impiden tomar y disponer de más recursos estatales, sin dimensionar las bases legales de un presupuesto estatal.

Esta política de incentivo al ahorro necesariamente debe consistir en un sobreprecio a todo consumo que supere el mínimo vital, para que, de esta manera, pueda controlarse a la vez los vertimientos a las fuentes de agua y, por ende, el Estado garantice el derecho humano al agua, que se materializa con el cuidado y protección de las fuentes hídricas.

Es muy cómodo hablar de poca atención del Estado en temas de servicios públicos, pero aun en tiempo de estados de excepción por el covid-19, no es tan flexible para las entidades territoriales ni para la a la nación disponer de recursos ilimitados para subsidios a costa del deterioro del medioambiente y sobre la marcha lograr buenos hábitos de consumo, para mitigar el daño de las fuentes o su agotamiento.

Como se expresó, resulta interesante, y podría verse como una oportunidad, volver a zonas menos pobladas para lograr que todas las decisiones estatales en materia de los servicios públicos domiciliarios tengan una mirada integrada del agua, y el servicio de agua potable no sea definido solo por un ministerio; y el agua como recurso tampoco sea direccionado por Ministerio Ambiente y Desarrollo Sostenible.

La pandemia, y es una hipótesis que surge, llevará a que el sector rural sea visto como una alternativa para el logro de las estrategias de distanciamiento social. Por ello, la inversión y la planificación debe dirigirse a él.

\section{Referencias}

Almanza, C. y Pérez, U. (2020). El control inmediato de legalidad en el marco del estado de emergencia económica, social y ecológica. Revista Jurídica Mario Alario D'Filippo, 12(24), 372-385.

Andesco (2020). ¿Qué pasa con el agua en plena emergencia por el nuevo coronavirus? https://www.andesco.org.co/ en/2020/04/06/que-pasa-con-el-agua-en-plena-emergencia-por-el-nuevo-coronavirus/

Becerra, J. y Salas, I. (2016). El derecho humano al acceso al agua potable: aspectos filosóficos y constitucionales de su configuración y garantía en Latinoamérica. Revista Prolegómenos Derechos y Valores, 19(37), 125-146. http://dx.doi.org/10.18359/prole.1683

Banco Interamericano de Desarrollo -BID. (2020). Salir del túnel pandémico con crecimiento y equidad: una estrategia para un nuevo compacto social en América Latina y el Caribe. Autor. Disponible en: https://bit. ly/2Qi9vik 
Banco Interamericano de Desarrollo -BID. (2012). Gobernanza y sostenibilidad de los sistemas de agua potable y saneamiento rurales en Colombia. Autor. Disponible en https://bit.ly/3uJVvg8

Bustos-Romero, M. (2016). Aproximación a la estructura sistemática del derecho administrativo económico colombiano. Justicia Juris, 12(1), 27-39.

Cifuentes-Muñoz, E. (2002). Los estados de excepción constitucional en Colombia. Ius et Praxis, 8(1), 117-146. https://dx.doi.org/10.4067/S0718-00122002000100009

Congreso de Colombia (1994, 11 de julio). De servicios públicos domiciliarios, por la cual se establece el régimen de los servicios públicos domiciliarios y se dictan otras disposiciones [Ley 142 de 1994]. Diario Oficial, No. 41 433. https://bit.ly/3w5ArRv

Congreso de Colombia (2011, 16 de julio). Por la cual se expide el Plan Nacional de Desarrollo, 2010-2014 [Ley 1450]. Diario Oficial, No. 48 102. https://bit.ly/3fh7dbN

Corte Constitucional, Sala Plena (2011, 29 de abril). Sentencia C-2016 [MP Juan Carlos Henao Pérez]. https://www.corteconstitucional.gov.co/RELATORIA/2011/C-216-11.htm

Corte Interamericana de Derechos Humanos -CIDH. (2020, 09 de abril). Covid-19 y derechos humanos: los problemas y desafíos deben ser abordados con perspectiva de derechos humanos y respetando las obligaciones internacionales. https://bit.ly/33IGy1X

Delgado, S., Cárdenas, J. y Fuentes, H. (2020). Los municipios de sexta categoría de Colombia (2000-2016): entre la autonomía y la dependencia. Apuntes del Cenes, 39(69),137-167. https://doi. org/10.19053/01203053.v39. n69.2020.10172

Dirección Nacional de Planeación -DNP y Superintendencia de Servicios Públicos Domiciliarios (2018). Estudio sectorial de los servicios públicos domiciliarios de acueducto y alcantarillado 2014-2017 (Informe sectorial 2014-2017). Autor. Disponible en https://bit. ly/3w2zHg3

Echeverría-Molina, J (2014). Los acueductos rurales frente a la política de coparticipación público-privada de los servicios públicos domiciliarios en Colombia: rezagos en materia de derechos fundamentales. En Los derechos humanos: Una mirada transdisciplinar (pp. 413438). Uninorte y Grupo Editorial Ibáñez.

Echeverría-Molina, J. y Anaya-Morales, S. (2018). El derecho humano al agua potable en Colombia. Decisiones del Estado y de los particulares. Vniversitas, 67(136), 1-14. https://doi.org/10.11144/Javeriana.vj136.dhap
Echeverría-Molina, J. y Nieto-Ariza, L. J. (2017). Prescripción de servidumbres de transmisión y de distribución de energía eléctrica. Revista Jurídicas, 14(2), 96-116. https://doi.org/10.17151/jurid.2017.14.2.7

Esparza, M. (2014). Drought and Water Shortages in Mexico. Current Status and Future Prospects. Secuencia, 89, 193-219.

Figueroa, E. (2020). Estados de excepción, covid-19 y derechos fundamentales, Revista Oficial del Poder Judicial. Órgano de Investigación de la Corte Suprema de Justicia de la República del Perú, 11(13), pp. 407-438. https://doi.org/10.35292/ropj.v11i13.5.

Kavulla, Ty de la Fuente L. J. (2020, 14 de julio). Las ventajas de las empresas de servicios públicos en la pandemia. El país. https:/cincodias.elpais.com/cincodias/2020/07/ 14/opinion/1594727573_195509.html

Llugdar, E. (2020). Límites del poder del Estado para restringir derechos en estados de excepción. Los límites de la pandemia de Covid 19. Colección Investigación Socio-Humanística del Derecho. Universidad Santo Tomás.

Manco, D., Guerrero, J. y Ocampo, A. (2012) Eficiencia en el consumo de agua de uso residencia. Revista Ingenierías, 11(21), 23-38.

Ministerio de Vivienda, Ciudad y Territorio de Colombia -Minvivienda. Comisión de Regulación de Agua Potable y Saneamiento Básico -CRA (2020, 17 de marzo). Por la cual se establecen medidas regulatorias transitorias en el sector de agua potable y saneamiento básico, derivadas de la emergencia declarada por el Gobierno Nacional a causa del COVID-19 [Resolución CRA 911 de 2020]. https://cra.gov.co/documents/RESCRA-911-2020.pdf

Ministerio de Vivienda, Ciudad y Territorio de Colombia -Minvivienda (2020, 11 de junio). Conozca cómo acceder al subsidio para el pago del servicio de agua rural. https://bit.ly/3hraIPy

Mira-González, C. (2016). Los estados de excepción en Colombia y aplicación del principio de proporcionalidad un análisis de seis casos representativos, Opinión Jurídica, 15(29), 141-163.

Nava-Escudero, C. (2018). Estudios ambientales. Instituto de Investigaciones Jurídicas. Universidad Autónoma de México.

Ocampo-Rodríguez Á. (2018, 20 de septiembre). Gobierno no avalará proyecto del mínimo vital gratuito de agua. RCN Radio https://www.rcnradio.com/politica/ gobierno-no-avalara-proyecto-del-minimo-vital-gratuito-de-agua 
Organización Mundial de la Salud -oms (2005) Directrices de la oms sobre higiene de las manos en la atención sanitaria (borrador avanzado): resumen. Autor. Disponible en https://bit.ly/3hrbADC

Organización Mundial de la Salud -oms (2017, 12 de julio). 2100 millones de personas carecen de agua potable en el hogar y más del doble no disponen de saneamiento seguro. https://bit.ly/3fh9d3x

ONU-Hábitat (2018). El derecho al agua (Folleto informativo No. 35). Autor. https://acnudh.org/el-derecho-al-agua-folleto-informativo-no-35/

ONU-Hábitat (2010). El derecho a una vivienda adecuada (Folleto informativo No. 21). Autor. https://www.ohchr.org/Documents/Publications/FS21_rev_1_Housing_sp.pdf

Presidencia de la República de Colombia (1994, 09 de junio). Por el cual se decreta el estado de emergencia por razón de grave calamidad pública [Decreto 1178]. Diario Oficial, No. 41 393. https://bit.ly/3p0vd7k

Presidencia de la República de Colombia (1999, 29 de enero). Por el cual se decreta el estado de emergencia económica, social y ecológica de grave calamidad pública [Decreto 195]. https://bit.ly/3wHZ1rX

Presidencia de la República de Colombia (2010, 07 de diciembre). Por el cual se declara el estado de emergencia económica, social y ecológica por razón de grave calamidad pública [Decreto 4580]. https://bit.ly/3p4tMoE

Presidencia de la República de Colombia (2020a, 20 de marzo). Por el cual se dictan disposiciones en materia de servicios públicos de acueducto, alcantarillado $y$ aseo para hacer frente al Estado de Emergencia Económica, Social y Ecológica declarado por el Decreto 417 de 2020 [Decreto 441]. https://bit.ly/3bvzwlG
Presidencia de la República de Colombia (2020b, 28 de marzo). Por el cual se adoptan medidas de urgencia para garantizar la atención y la prestación de los servicios por parte de las autoridades públicas y los particulares que cumplan funciones públicas y se toman medidas para la protección laboral y de los contratistas de prestación de servicios de las entidades públicas, en el marco del Estado de Emergencia Económica, Social y Ecológica [Decreto 491]. https://bit.ly/3ydRJ0F

Presidencia de la República de Colombia (2020c, 25 de marzo). Por el cual se modifica el Decreto 1068 de 2015, Decreto Único Reglamentario del Sector Hacienda y Crédito Público, en lo relacionado con operaciones de crédito público cuya celebración no comprenda la financiación de gastos de inversión [Decreto 473]. https://bit.ly/3hwfBqk

Presidencia de la República de Colombia (2020d, 15 de abril). Por el cual se dictan medidas en materia de los servicios públicos de acueducto, alcantarillado y aseo, en el marco del Estado de Emergencia Económica, Social y Ecológica [Decreto 580]. https://bit.ly/3okualC

Restrepo, E y Zárate, C. (2016). El mínimo vital de agua potable en la jurisprudencia de la Corte Constitucional colombiana. Opinión Jurídica, 15(29), 123-140.

Tobón, M. y Mendieta, D. (2017). Los estados de excepción en el régimen constitucional colombiano. Opinión $\mathrm{Ju}$ rídica. 16, 67-88. https://www.doi.org/10.22395/ojum. v16n31a3

Vanegas-Gil, P. (2011). La Constitución colombiana y los estados de excepción: veinte años después. Revista Derecho del Estado, 27, 261-290.

Ylarri, J. S. (2020). Los estados de excepción y las situaciones que habilitan su declaración. Un estudio desde el derecho comparado. Revista Jurídica Austral, 1(1), 219-273. 